\title{
Modelling the location of self-employed workers in urban areas
}

\author{
José Ignacio Giménez-Nadal, University of Zaragoza, BIFI (Spain) \\ Jorge Velilla, University of Zaragoza (Spain)
}

\begin{abstract}
In this paper, we develop an urban model for self-employment where leisure and effort at work are complementary. Our model shows that unemployment tends to be concentrated far from business districts, in contrast to employment and self-employment. The selfemployed tend to live closer to workplaces than do the employed, as commuting affects productivity and thus earnings. We use the American Time Use Survey to test the model, and find that employment and self-employment are negatively related to commuting, in comparison to unemployment, while self-employment is associated with shorter commutes, giving support to the theoretical background.
\end{abstract}

Keywords: Self-employment; commuting; shirking. 


\section{Introduction}

The analysis of the relationship between commuting and wages has been modeled by urban efficiency wages theory, where leisure and shirking are substitutes, and more commuting time is related to less time in leisure, increasing worker's incentives to shirk (Ross and Zenou, 2008; Gimenez-Nadal et al., 2018a). However, the literature has been focused on employed workers, and self-employed workers have not been analyzed, despite the fact that self-employed workers are also limited in their working days by their commuting choices. Likewise, we develop an urban model where self-employed workers are included, using urban efficiency wages theory, and that is able to explain the differential behavior of self-employed workers in comparison to employees. ${ }^{1}$

We empirically test the predictions of the model using the American Time Use Survey (ATUS) for the period 2003-2014. We find that the probability of being employed or selfemployed is negatively related to expected commuting times, relative to the unemployed. Furthermore, longer commuting is related to a lower probability of self-employment, in favor of the probability of being an employee. Additionally, we empirically study the main hypothesis of the model, and find a negative relationship between leisure and shirking among self-employed workers. Thus, our theoretical results are in line with both the hypothesis and predictions of the model.

\section{Theoretical Model}

This model is based on the urban efficiency wages model of Ross and Zenou (2008), where leisure and effort are work are assumed to be substitutes. Assume that selfemployment outcome is represented by a production function, $F(e)$, with $e$ being worker effort at work, $F^{\prime}(e)>0$. We consider a linear, monocentric and closed city where the Central District, $\mathrm{CD}$, is located at $x=0$, and the city fringe at $x=1$, and all jobs are located at the CD. Workers are risk-neutral, do not have inter-temporal preferences, can be unemployed, employees, or self-employed, and endogenously decide their residential location, $x \in(0,1)$, and their effort at work, $e$. There are infinite moving costs, and the population is normalized to 1 .

\footnotetext{
${ }^{1}$ The relationship between self-employment and commuting has rarely been studied (van Ommeren and van der Straaten, 2008; Gimenez-Nadal et al., 2018b).
} 
The process behind the transitions between employment, self-employment and unemployment is governed by Markovian processes. We assume a rate $\theta$ of abandoning unemployment. Then, individuals go to a fictitious intermediate state that leave to become self-employed, with a probability $p_{1}$, or finding an employer, with probability $p_{2}$. The self-employed and employees become unemployed at a rates $\delta_{1}$ and $\delta_{2}$, respectively. Then, we can obtain the percentage of life that workers will be unemployed, $u=\frac{\delta_{1} \delta_{2}}{\alpha}$, self-employed, $s e=\frac{\theta \delta_{2}}{\alpha}$, and employed, $w e=\frac{\theta \delta_{1}}{\alpha}$, with $\alpha=\delta_{1} \delta_{2}+\theta \delta_{2}+\theta \delta_{1}$.

Following Ross and Zenou (2008), we define an instant utility:

$$
z+V(l, e)
$$

where $z$ is the consumption of goods (at unitary prices), and $V(l, e)$ is the instant utility from leisure $(l)$ and effort at work, with $\frac{\partial V(l, e)}{\partial l}>0, \frac{\partial V(l, e)}{\partial e}<0$, and $\frac{\partial^{2} V(l, e)}{\partial l \partial e}>0$, so less leisure increases in the benefits from shirking, which is the main assumption of Ross and Zenou (2008). We assume that $l=l(x)$, with $l^{\prime}(x)<0$, fixed and exogenous wages, $w$, working times, $T$, and normalize the total available time to 1 . This leads to the following expression of workers life-cycle utility:

$I(x, e)=\frac{\theta \delta_{1}}{\alpha} w T+\frac{\theta \delta_{2}}{\alpha} F(e)+\frac{\theta\left(\delta_{1}+\delta_{2}\right)}{\alpha} V(1-T-t x, e)+\frac{\delta_{1} \delta_{2}}{\alpha} I_{u}-\frac{\theta\left(\delta_{1}+\delta_{2}\right)}{\alpha} \tau x-$ $R(x)$.

where $R(x)$ is the cost of living at $x, R^{\prime}(x)<0$.

Following Ross and Zenou (2008), there are two types of workers: those who shirk and those who do not shirk, with two levels of effort at work, $e_{0}$ and $e_{1}, e_{0}<e_{1}$. As shirkers workers may be caught shirking according to a monitoring technology $m>0$, and their self-employment outcome is also lower, their expected times in employment, self-employment and unemployment differ from non-shirkers: $u_{0}=\frac{\left(\delta_{1}+m\right)\left(\delta_{2}+m\right)}{\beta}, w e_{0}=$ $\frac{\theta\left(\delta_{1}+m\right)}{\beta}$, and $s e_{0}=\frac{\theta\left(\delta_{2}+m\right)}{\beta}$, with $\beta=\left(\delta_{1}+m\right)\left(\delta_{2}+m\right)+\theta\left(\delta_{2}+m\right)+\theta\left(\delta_{1}+m\right)$. The life-cycle utility of shirkers can be then written as:

$$
\begin{aligned}
I_{0}=\frac{\theta\left(\delta_{1}+m\right)}{\beta} w T & +\frac{\theta\left(\delta_{2}+m\right)}{\beta} F\left(e_{0}\right)+\frac{\theta\left(\delta_{1}+\delta_{2}+2 m\right)}{\beta} V\left(1-T-t x, e_{0}\right)+ \\
& +\frac{\left(\delta_{1}+m\right)\left(\delta_{2}+m\right)}{\beta} I_{u}-\frac{\theta\left(\delta_{1}+\delta_{2}+2 m\right)}{\beta} \tau x-R(x) .
\end{aligned}
$$


In that context, the first result of the model claims that non-shirker workers tend to spend less time unemployed during their life-cycle, as $u_{0}>u_{1}$. Furthermore, by clearing $R(x)$ in (2) and (3), we obtain the bid rent functions of workers, i.e., the amount that they are willing to pay for a unit of land in $x$. As $R(x)$ is found to be steeper for non-shirkers than for shirkers, the former are willing to pay more than the latter for living near job places, which is the second main result of the model.

\section{Data}

We use the ATUS data for the years 2003 to 2014. We restrict the sample to unemployed, self-employed, or employed individuals between 16 and 65 years. For employed and selfemployed workers, we consider only days when individuals spend more than 60 minutes working, to avoid computing zero minutes of commuting to any employed or selfemployed worker who filled out the time-use diary on a non-working day. These restrictions leave us with 31,343 employees, 5,290 self-employed, and 4,696 unemployed individuals.

We define commuting time as the time of commuting to/from work (code "180501" in the ATUS), measured in minutes per day. One important issue is that commuting time is not observed for the unemployed. To overcome this problem, we follow GimenezNadal et al. (2018a) and predict commuting for the unemployed by the interaction of housing stock variables and region variables, exploiting systematic differences between the structures of metro areas. The commuting model is shown in Table A1 in the Appendix. We also define the daily minutes spend by workers in leisure and shirking activities. Shirking includes the total time spent at the workplace that is not market work (Burda et al., 2016; Gimenez-Nadal et al., 2018a). Summary statistics of the main variables are shown in Table A2 in the Appendix. Other control variables include gender (being male), potential years in labor market (age, minus education years, minus 3 ) and its square, education, living in couple, partner's labor-force status, number of children, being white, and being American, Asian, or Pacific Islander.

\section{Results}

We first regress a dummy that takes value 1 if individuals are employed/self-employed, 0 if unemployed, in terms of the expected commuting time of individuals, the set controls, 
and MSA fixed effects. Given that expected commutes are predicted variables, we bootstrap the standard errors (Pagan, 1984). The main results are shown in Column (1) of Table 1. We find that one more minute of expected commuting is significantly associated, on average, with increases in the probability of being unemployed of $3.9 \%$. This estimate is in line with the results of the model and suggests that the employed and the selfemployed live closer to the business centers, compared to the unemployed.

Table 1: Main estimates

\begin{tabular}{|c|c|c|c|}
\hline VARIABLES & $\begin{array}{c}\text { (1) } \\
\text { Employed vs } \\
\text { unemployed }\end{array}$ & $\begin{array}{c}\text { (2) } \\
\text { Self-employed vs } \\
\text { employees }\end{array}$ & $\begin{array}{c}4) \\
\text { Leisure time } \\
\text { (self-employed) }\end{array}$ \\
\hline Expected commuting & $\begin{array}{c}-0.039 * \\
(0.020)\end{array}$ & - & - \\
\hline Commuting & - & $\begin{array}{c}-0.042 * * * \\
(0.002)\end{array}$ & - \\
\hline Shirking & - & - & $\begin{array}{c}-0.168 * * * \\
(0.024)\end{array}$ \\
\hline Constant & $\begin{array}{c}0.775 * * * \\
(0.069)\end{array}$ & $\begin{array}{c}0.047 * * \\
(0.022)\end{array}$ & $\begin{array}{c}2.119 * * * \\
(0.385)\end{array}$ \\
\hline Sociodemographics & Yes & Yes & Yes \\
\hline Housing characteristics & Yes & Yes & Yes \\
\hline Observations & 41,329 & 36,633 & 5,290 \\
\hline
\end{tabular}

We next drop the unemployed from the sample, and run a similar regression where the dependent variable is a dummy that takes value 1 if individuals are self-employed, 0 if employees. Estimates are shown in Column (2) of Table 1. Results indicate that one additional minute of commuting is associated with a decrease of $4.2 \%$ in the probability of being self-employed (vs. being employed). The implication of this result is that the self-employed live closer to their respective workplaces, in comparison to the employed, consistent with the idea that self-employed workers devote less time commuting than do employees. $^{2}$

Finally, we explore the main assumption of the model, that of a substitution relationship between leisure and shirking. In doing so, we regress in Column (3) of Table 1 the log-time spent in leisure activities by self-employed workers against the log-time spent shirking, and the set of control variables. We observe a significant elasticity

\footnotetext{
${ }^{2}$ Given that commutes are likely endogenous, we have repeated the analysis instrumenting commuting time using the commuting model shown in the Appendix. Results are robust to the general case.
} 
between leisure and shirking of -0.168 , thus concluding that the idea of substitution between leisure and shirking is not solely applicable to employees, and that urban models of self-employment should take that into account.

\section{Conclusions}

This paper analyzes employment and self-employment in an urban context, where leisure and effort at work are complementary concepts, finding that the self-employed tend to live nearer their workplaces than employees according to the theoretical model. Using the ATUS for the years 2003-2014, our empirical results show that employment and selfemployment are negatively related to commuting, in comparison to unemployment. Furthermore, self-employment is associated with shorter commutes, in comparison to wage employment. Our results contribute to the literature by offering a new theoretical and empirical study of self-employment in the United States.

Acknowledgements: This paper has benefitted from funding from the Government of Aragón (Project S32-17R, co-financed by FEDER 2014-2020). J. Velilla gratefully acknowledges funding from the Government of Aragón Doctoral Grants (Program FSE Aragón 2014-2020).

Declaration of interest: No potential conflicts declared by authors.

\section{References}

Burda, M, K.R. Genadek and D.S. Hamermesh (2016). "Not working at work: Loafing, unemployment and labor productivity.” NBER WP No. 21923.

Gimenez-Nadal, J.I., J.A. Molina and J. Velilla (2018a). "Spatial distribution of US employment in an urban efficiency wage setting." Journal of Regional Science 58 (1): 141-158.

Gimenez-Nadal, J.I., J.A. Molina and J. Velilla (2018b). "The commuting behavior of workers in the United States: differences between the employed and the selfemployed." Journal of Transport Geography 66 (1): 19-29. 
Pagan, A. (1984). "Econometric issues in the analysis of regressions with generated regressors." International Economic Review 25 (1): 221-247.

Ross, S.L., and Y. Zenou (2008). “Are shirking and leisure substitutable? An empirical test of efficiency wages based on urban economic theory." Regional Sciences and Urban Economics 38(5): 498-517.

Van Ommeren, J.N. and J.W. van der Straaten (2008). "The effect of search imperfections on commuting behavior: Evidence from employed and self-employed workers." Regional Science and Urban Economics 38 (2): 127-147. 